\title{
La felicidad en publicidad desde la perspectiva del neuromarketing
}

Happiness in advertising from a neuromarketing perspective

Héctor Canorea Tiralaso, Universidad Internacional de la Rioja - hectorcnti@hotmail.com

Carmen Cristofol Rodríguez, Universidad Internacional de la Rioja - carcrir@uma.es

\section{Resumen}

La felicidad siempre ha sido perseguida por los seres humanos y la sociedad de consumo ha elevado esta búsqueda hasta su máximo nivel. Por ello, en la presente investigación, hacemos una revisión bibliográfica de dicho concepto y su relación con las marcas, desde el ámbito del neuromarketing. La sociedad consumista gira en torno a la felicidad, que necesita ser experimentada de forma plena e inmediata (Bauman, 2007, p.38). De esta forma, muchos expertos señalan que existe una "industria de la felicidad" entorno a las marcas, que ha conseguido que ésta se instale como la máxima en la vida de los consumidores (Montagut, 2007). Los neurocientíficos sostienen que las emociones dominan a la razón, puesto que primero sentimos y luego pensamos. Así, se señala que el $85 \%$ de las decisiones son tomadas de forma automática sin que medie la reflexión (Feenstra, 2013). Pese a que la felicidad es un concepto muy utilizado por las marcas, son pocos los estudios que han tratado de relacionar estos términos con el comportamiento del consumidor y su relación con las marcas (Lysonski, 2014). El Neuromarketing, brinda posibilidad de visualizar la conexión de los espectadores con las marcas y sus efectos sobre ellos.

\section{Palabras clave}

Felicidad, cerebro, placer, neuromarketing, marcas, toma de decisiones

\section{Abstract}

Happiness has always been persecuted by human beings and the consumer society has raised this search to its highest level. Therefore, in the present investigation, we make a literature review of this concept and its relationship with brands, from the field of neuromarketing. The consumer society revolves around happiness, which needs to be fully and immediately experienced (Bauman, 2007, p.38). In this way, many experts point out that there is a "happiness industry" around brands, which has ensured that it is installed as the maximum in the lives of consumers (Montagut, 2007). Neuroscientists maintain that emotions dominate reason, since we first feel and then think. Thus, it is pointed out that $85 \%$ of decisions are made automatically without reflection (Feenstra, 2013). Although happiness is a concept widely used by brands, few studies have tried to relate these terms to consumer behavior and its relationship with brands (Lysonski, 2014). Neuromarketing offers the possibility to visualize the connection of the spectators with the brands and their effects on them.

\section{Keywords}

Happiness, brain, pleasure, neuromarketing, brands, decision making

1. Introducción. 2. Metodología. 3. Revisión de la literatura: La felicidad y las marcas. 3.1. El relato de la felicidad en la publicidad. 3.2. Marcas que han usado el concepto de felicidad. 3.3. Beneficios del uso de la felicidad para las marcas. 4. Cómo crear felicidad en el consumidor. 4.1. Cómo se produce la felicidad a nivel cerebral. 4.2. Influencia de las emociones en la conducta del consumidor. 4.3. La memoria y el proceso de compra. 5. Conclusiones. 6 . Bibliografía. 


\section{Introducción}

El presente trabajo tiene como objetivo principal hacer una profunda revisión bibliográfica de la relación entre las marcas y el concepto de felicidad. Este tema ha atraído profundamente la atención e interés tanto de profesionales del sector como de académicos. De este objetivo principal se derivan una serie de objetivos complementarios:

- Investigar el concepto de felicidad en relación a las marcas.

- Estudiar la influencia de las emociones en la toma de decisiones de los consumidores, especialmente la felicidad y desde el punto de vista del neuromarketing.

- Conocer cuáles son los beneficios que tiene el uso de la felicidad como reclamo para las marcas.

\section{Metodología}

Para la elaboración del presente trabajo, se ha procedido a una profunda revisión de literatura académica acerca del tema objeto de estudio, para de esta forma obtener conclusiones empíricas sobre la relación existente entre las marcas y el concepto de felicidad que responda a todas las preguntas planteadas como guía de la investigación. Para ello se ha recurrido a una metodología cualitativa mediante la recopilación de información de fuentes de tipo secundario tales como libros, artículos y estudios relacionados con el objeto de estudio de la investigación. Para la búsqueda bibliográfica sobre la cual se ha sustentado el presente trabajo, se han usado las bases documentales de mayor impacto y unos criterios de selección para delimitar la muestra.

\section{Revisión de la literatura: La felicidad y las marcas}

Es tal el nivel de desarrollo del ámbito del marketing que muchos expertos señalan que existe una "industria de la felicidad" entorno a las marcas, que ha conseguido que la felicidad se instale como la máxima en la vida de las personas (Montagut, 2007). Belén López Vázquez (2007) afirma que las marcas deben proporcionar a través de su comunicación estímulos basados en el placer y en el bienestar para dejar en ellos una huella que perdure en la memoria.

\subsection{El relato de la felicidad en la publicidad}

Relacionar publicidad y felicidad no es algo novedoso, puesto que la publicidad desde sus inicios, ha utilizado una propuesta de venta implícita de felicidad, la cual se alcanza mediante el consumo de los productos que se publicitan (Eguizábal, 2007: 174)

Con el apoyo de los medios de comunicación, especialmente la televisión, la publicidad instala el concepto de felicidad de una forma sencilla en la mente del consumidor: primero subraya o crea una insatisfacción (ya sea material o psicológica) en el consumidor, insatisfacción que se resuelve con el producto o servicio que aparece el anuncio (Pellicer, 2013). Desde la perspectiva neurocientífica, la publicidad activa en la mente del consumidor una serie de procesos en los circuitos de la memoria, el afecto (la recompensa) y el pensamiento. Si estas reacciones no se produjeran a nivel cerebral, el anuncio no lograría influir en la toma de decisión del consumidor (Pretel, 2017).

Se ha demostrado que los sentimientos evocados por los anuncios contribuyen significativamente en la actitud y respuestas emocionales que desarrollan los clientes hacia el anuncio y hacia la propia marca (Holbrook y Batra, 1987). Así, la televisión y la publicidad crean un mercado de sensaciones, el cual se pone a disposición de un público que disfruta consumiendo imágenes placenteras asociadas a las marcas (Martínez-Rodrigo y Segura-García, 2013). De esta forma, las marcas crean mediante el empleo de la publicidad fantasías en las que la adquisición de productos lleva a alcanzar la felicidad (Chicaiza, 2012). No obstante, se trata de una felicidad efímera, de ahí la necesidad de un consumo constante (Ruiz, 2010).

La cuestión que cabe plantearse es por qué la publicidad ha elegido a la felicidad como argumento principal de venta, ya que existen otros muchos elementos inmateriales a los que poder hacer referencia y con los que poder vender los diferentes productos y servicios que ofrecen las marcas. La respuesta reside en la ansiada búsqueda de la felicidad compartida por todas las culturas y presente en todos los seres humanos (Pellicer, 2013).

Para la creación de esa sensación de felicidad sobre el consumidor, la publicidad se vale de lo que se denomina el Happiness Halo, que consiste en la ilusión de ser felices. De esta manera, no es la experiencia en sí o el producto que se promociona a través de la publicidad, sino la idea de lo que todo esto podrá suponer. La idea de la felicidad, por tanto, se construye partiendo de la anticipación a la misma y de la memoria de lo que ha ocurrido en otras ocasiones. Esto fue confirmado por Senik (2006), quien realizó un estudio empírico en el que se concluía que el mero hecho de aspirar a un consumo mayor es un elemento que aporta felicidad, aunque este consumo no termine llevándose a cabo. Las marcas crean ese "halo de felicidad" de dos formas diferentes. Por un lado, pueden hablar de forma directa de la felicidad como por ejemplo lo hace marca Coca-Cola con eslóganes como "Destapa la felicidad". La segunda forma en que transmiten el mensaje de felicidad, es recreando el concepto mediante la historia y actitud de los personajes (Pellicer, 2013).

Si bien existen muchas formas de entender y definir la felicidad, existen una serie de patrones comunes en la publicidad que transmiten esta emoción como son el uso de colores cálidos, imágenes de personas con una vida plena y música armoniosa (Imfeld,2015).

La obsesión por la felicidad, no obstante, ha sobrepasado la esfera de los individuos para instalarse también, como se ha visto anteriormente, en los discursos económicos que señalan la felicidad como una medida del bienestar de la sociedad (Amigot y Aguilar, 2003). De esta forma, existe dentro de la economía una rama, la economía emocional, que estudia aspectos del comportamiento humano relacionados con el consumismo exacerbado y la voracidad competitiva existentes en la actualidad (Schuschny, 2009). En la economía emocional se considera que las empresas se valen del entretenimiento y las historias para hacer felices a la gente y crear vínculos emocionales con los consumidores. Las empresas ya no ofrecen al mercado tan solo productos y servicios que satisfacen necesidades, sino que son productos y servicios, que presentan significado para los consumidores. Lo explica Zaltman de forma precisa: 
(...) el significado de una marca reside en la mente de los consumidores, no en la propia marca ni en la publicidad que se hace sobre ella. Es decir, son los consumidores, no las empresas, quiénes crean, en definitiva, el significado de la marca. Este significado surge de la relación entre los mapas de consenso de los consumidores y sus experiencias con las marcas (Zaltman, 2004: 99).

El concepto de felicidad es un valor en alza (Muñiz y Álvarez, 2013) debido al contexto de crisis este se ha visto más utilizado como recurso publicitario. De esta forma, la mayor parte de sectores de productos cuenta con marcas o anunciantes que se relacionan mediante sus discursos publicitarios sobre elementos que transmitan felicidad.

\subsection{Marcas que han usado el concepto de felicidad}

Son numerosas las marcas que han utilizado la felicidad en su eslóganes y campañas de publicidad, marcas como por ejemplo Coca-Cola, Danone, Finish, McDonald's, Cadbury, Frigo, Media Markt, Carbury, Nesquik o H\&S, por citar solo algunas, viéndose el consumidor invadido y rodeado completamente por estímulos referentes a la felicidad. Otras no han mencionado la felicidad de forma directa, pero este concepto se encontraba detrás de sus promesas de marca como, por ejemplo, Disneyland con "Dónde los sueños se hacen realidad", El Corte Inglés y su clásico "Si no queda satisfecho le devolvemos el dinero", Nestlé "A gusto con la vida" o Beldent "Contagiemos la risa".

Algunas marcas han apelado a la felicidad creando un logotipo que de algún modo transmita este mensaje. Este es el caso por ejemplo de marcas como Amazon, Pepsi, Matutano, Hasbro o Danone, las cuales presentan el símbolo de una sonrisa en sus respectivos logotipos.

Las empresas y marcas han utilizado tanto la promesa de la felicidad, la palabra y el propio concepto que han dejado al mismo sin sentido. De esta forma un directivo de Coca-Cola, la marca que mejor ha utilizado el concepto de felicidad en su publicidad, afirmaba que "La felicidad se ha convertido en una palabra sobre utilizada en la cultura actual y contemporánea".

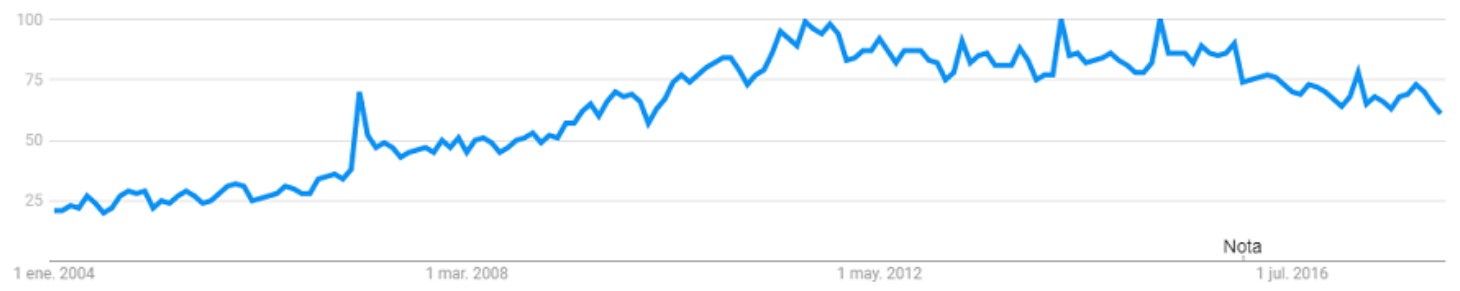

Ilustración 1. Evolución búsquedas relacionadas con la felicidad de 2004-2016 (Fuente: Puro Marketing, 2018).

El uso excesivo de este reclamo por parte de las marcas ha provocado la necesidad de destacar de impactar de una forma más profunda en el corazón del consumidor, creando una insatisfacción más grande (Pellicer, 2013). Por este motivo, son muchos los estudios que han tratado de encontrar aquellos aspectos del consumo que pueden intensificar la sensación de felicidad que experimentan los consumidores (Carter et al., 2010).

\subsection{Beneficios del uso de la felicidad para las marcas}

Estudios realizados han confirmado que la felicidad que experimentan y asocian los consumidores a una marca, tiene una influencia positiva en su percepción de la calidad de la misma. Así, según Gardner (1985) el estado de ánimo del consumidor influye en la evaluación que hace sobre las marcas y productos. De esta forma, un estado de ánimo positivo (Clark e Isen, 1982) suele llevar en mayor proporción a opiniones positivas sobre marcas y productos.

También se ha observado que influye en la lealtad que los consumidores poseen hacia dichas marcas, demostrándose así la clara relación que existe entre felicidad y consumo (Hsee et al., 2009). No obstante, son pocos los estudios que han estudiado la relación entre la felicidad y la lealtad de marca (Silvera et al., 2008; Chiu et al., 2013).

Por otro lado, los consumidores que en la sociedad moderna pretenden experimentar la felicidad de forma continua, tenderán a evitar el riesgo de consumir otras marcas diferentes a las que utilizan habitualmente para evitar la posible decepción e infelicidad que le pueda acarrear la nueva experiencia de marca (Podoshen y Andrzejewski, 2012).

Los consumidores valoran que las marcas tomen un posicionamiento emocional y que se preocupen de su felicidad. Así quedo patente en una investigación realizada por Zenith Optimedia en distintos países al segmento de la población denominado como Millenials. Así estos afirmaban que la marcas debían proporcionarles felicidad y libertad (Imfeld, 2015).

Un estudio realizado por Nicolao, Irwin y Goodman (2009) concluyó, al igual que habían hecho anteriormente Van Boven y Gilovich (2003), que la felicidad derivada de las experiencias es superior a la que se produce en las compras materiales.

\section{Cómo crear felicidad en el consumidor}

La creciente atención que ha generado la felicidad, también se ha visto reflejada en el ámbito de los negocios, donde se ha comenzado a investigar cómo pueden las marcas crear la felicidad de los consumidores (Isen, Labroo, \& Durlach 2004; Mogilner and Aaker 2009).

Según Estrella Fernández, consultora en Marketing y Retail y especialista en Neurociencia Cognitiva y Neuropsicología, la mayor parte de las marcas: 
Opta por generar expectativas de felicidad en base a la adquisición de circunstancias y objetos, lo que está bien porque estimula el deseo pero, por el contrario, debido a ese proceso de adaptación hedónica, una vez se consume el deseo o los objetivos se vuelve a tener un sentimiento de insatisfacción (Eada, 2015)

De esta forma, según Estrella Fernández, esto produce una espiral continua de deseo, logro e insatisfacción que activa los sistemas de recompensa de forma incesante, así como los sistemas de defensa, vinculados con la ansiedad y el estrés, debido a las necesidades insatisfechas. Este modelo, por tanto, no parece muy acertado si produce también insatisfacción en los consumidores. Aparte, "no debemos engañarnos con la dopamina, pues va muy bien para estimular el deseo pero no genera lealtad -por ejemplo, nos permite estar enamorados de 10 marcas a la vez" (Eada, 2015).

La satisfacción del consumidor que se derivará en la felicidad del mismo debe por tanto derivarse de un profundo análisis de cuáles son las fuentes de placer en las personas. Precisamente esto es el objetivo del neuromarketing, entender por medio de los recursos que ofrece las neurociencias para determinar los procesos en los cuales el cerebro reacciona ante el placer (Dávila, 2013).

\subsection{Cómo se produce la felicidad a nivel cerebral}

La forma utilizada de forma tradicional en la mayor parte de las investigaciones para medir felicidad es el auto reporte, que no es una medida objetiva sino subjetiva. Esta forma de medir felicidad deriva de los estudios de psicología, cuyos estudios han tenido que lidiar con el uso de variables subjetivas (Caravaggio, 2016). No obstante, frente a otros aspectos como las patologías, el estudio de la felicidad ha sido bastante ignorado en la psicología moderna. De esta forma resulta todavía necesario encontrar la forma de objetivar el estudio de la felicidad (Funahashi, 2011). Esto es debido según Franco Berardi a que la felicidad no puede ser objeto de estudio científico, sino que debe limitarse a ser un objetivo ideológico. Berardi razona esto apuntando a que no es posible la valoración cuantitativa de la misma. No obstante, y aunque todavía no existe consenso, hay autores como Chemali, Chahine y Naassan que proponen modelos cerebrales de la felicidad.

No se puede señalar una región cerebral específica que se identifique con la felicidad, sino que más bien parece que existe una amplia correlación entre varias estructuras neurales (Morgado y Cuquerella, 2015; Funahashi, 2011). Algunos estudios han apuntado el área cerebral denominada orbitofrontal por su amplio abanico de conexiones con el sistema dopaminérgico (responsable del deseo), el sistema opioideo (responsable del placer) y estructuras neurales como los ganglios basales, la ínsula, el área medial prefrontal y el córtex cingulado (Morgado y Cuquerella, 2015).

\section{Principales experiencias que siempre busca el cerebro}

\begin{tabular}{|c|c|c|}
\hline $\begin{array}{l}\text { Búsqueda de lo } \\
\text { novedoso, sorpresivo } \\
\text { e inesperado. }\end{array}$ & NORADRENALINA & $\begin{array}{l}\text { Muestrame las cosas desde un } \\
\text { ángulo que nunca había visto. } \\
\text { Abre mi abanico de posibilidades. }\end{array}$ \\
\hline $\begin{array}{l}\text { Indulgencia, } \\
\text { facilidad } \\
\text { y recompensa. }\end{array}$ & DOPAMINA & $\begin{array}{l}\text { Hazme sentir inteligente. } \\
\text { Dame la razón. } \\
\text { Muéstrame valores agregados. } \\
\text { Hazme sentir único. }\end{array}$ \\
\hline $\begin{array}{l}\text { Aprendizaje, } \\
\text { adaptabilidad } \\
\text { y asociación de } \\
\text { elementos conocidos. }\end{array}$ & ACETILCOLINA & $\begin{array}{l}\text { Enséñame. } \\
\text { Ayúdame a relacionar } \\
\text { y contextualizar las cosas } \\
\text { a mi mundo. }\end{array}$ \\
\hline Quitar el dolor. & ENDORFINA & $\begin{array}{l}\text { Aligera mi carga. } \\
\text { Dame soluciones. } \\
\text { Permiteme normalizar. } \\
\text { Hazme sentir comprendido. }\end{array}$ \\
\hline $\begin{array}{l}\text { Vivir emociones: } \\
\text { sentirlas } \\
\text { y expresarlas. }\end{array}$ & SEROTONINA & $\begin{array}{l}\text { Transmiteme tus emociones } \\
\text { y sensibilizate hacia las mías. }\end{array}$ \\
\hline
\end{tabular}

Ilustración 2. Cuadro resumen de neurotransmisores que intervienen en la sensación de felicidad (Fuente: Klaric, 2016:113)

Si bien la zona orbitofrontal ha sido señalada por diversas investigaciones como una estructura que interviene en la experiencia subjetiva de la felicidad, todavía no se ha demostrado si realmente lo que causa son emociones positivas o placer (Funahashi, 2011). Si como parece lógico pensar la felicidad está ligada a la sensación de placer, el núcleo caudado tendría un papel importante en la experiencia de la misma. Esto se puede deducir de los estudios llevados a cabo en el Instituto Douglas de Montreal, de los cuales se desprende que las personas que sufren anhedonia (incapacidad para sentir placer y satisfacción) se caracterizan por poseer un núcleo caudado de menor tamaño que aquellas otras que no padecen este trastorno (Morgado y Cuquerella, 2015).

Por tanto, es todavía necesaria la realización de más estudios para tener una comprensión mejor de las dinámicas cerebrales implicadas en la felicidad.

\subsection{Influencia de las emociones en la conducta del consumidor}

La consideración de las emociones en el ámbito de la investigación publicitaria es un fenómeno reciente, tanto desde una perspectiva teórica como empírica. En lo referente a la publicidad emocional, esta lleva poco tiempo centrando el interés de los investigadores, motivo por el cual la cantidad 
de referencias en este tema todavía sea poco abundante y esté bastante fragmentada (Ceruelo \& Gutiérrez, 2003). No obstante, como expone Punset:

En muy pocos años se ha pasado de una situación en la que las emociones no formaban parte del mecanismo de toma de decisiones, ni merecían más que rechazo, a otra en la que se agolpan tanto en el inicio de los proyectos que se pretenden llevar a buen puerto, como en la decisión final con la que suele culminar una reflexión (Punset, 2005: 61).

Según Hernández, Gómez y Barrios (2011) que evaluaron la aceptación de las marcas por los clientes, los atributos intangibles de las marcas se relacionan con índices más altos de involucramiento por parte de los consumidores, que los atributos tangibles. Según las autoras, cuando se evalúan las marcas preferidas, los atributos juegan un papel esencial en el posicionamiento fuerte en la mente del consumidor, lo que lleva a la diferenciación de unas marcas frente a otras. En el análisis realizado por IPA dataBANK de Inglaterra, basado en el análisis de 1.400 campañas publicitarias exitosas, se concluyó que las campañas de carácter emocional tuvieron mejores resultados que las racionales. De esta forma, el $31 \%$ de las campañas eran emocionales y tan sólo un $16 \%$ apelaba a la razón de los consumidores. Esto también se extrae del estudio de Marketing in the Age of Accountability (Binet y Field, 2010), que a raíz de una revisión de los IPA Awards, premios que reconocen las campañas más eficaces de Gran Bretaña con una base de más de 1000 casos parametrizados, concluye que:

- Las estrategias de comunicación basadas en emociones tienden a generar mejores resultados que los puramente racionales.

- Las campañas emocionales alcanzan un impacto mayor en ventas, cuota de mercado, margen, penetración, lealtad, sensibilidad al precio, etc.

- Las campañas emocionales tienen un desempeño muy superior a las racionales en casi todas las métricas actitudinales (especialmente en notoriedad de marca y diferenciación de marca).

Por tanto, se puede concluir, tal y como señalan Conner y Norman (2005), que las empresas deben ofrecer experiencias únicas a los consumidores a través de vínculos emocionales para destacar frente a los competidores.

Humberto Maturana (1990) ha estudiado ampliamente la relación entre las emociones y la razón, y señala que el ser humano utiliza la razón para justificar u ocultar sus emociones. Para Ambler las emociones influyen en publicidad en dos momentos diferentes. El primero permitiendo captar la atención del consumidor y el segundo cuando las decisiones de consumo ya se han tomado. De esta forma, según Maturana el autodenominado como "Homo Sapiens" basa sus decisiones más en las emociones que en el raciocinio, que es utilizado para explicar a posteriori las decisiones y conductas del ser humano. Las emociones, por tanto, guían la toma de decisiones, simplificando y acelerando el proceso, reduciendo el nivel de complejidad de la decisión y disminuyendo el conflicto que se pueda producir entre diversas opciones (Martínez-Selva et al., 2006). Así, en el libro Lovemarks, escrito por Kevin Roberts (2005), se remarca la importancia de las emociones para los seres humanos en la cita que recoge de Maurice Levy:

La mayoría de la población consume y compra con la cabeza y el corazón o, si lo prefieren, con emociones. Buscan con una base racional: qué hace el producto y por qué es la mejor elección. Pero su decisión es emocional: me gusta, lo prefiero, me produce una buena sensación. Antes de comprender, sentimos. Y es esencial hacer que las personas se sientan bien con las marcas y que éstas despierten sensaciones positivas. Es lo que marca la diferencia (Levy, citado por Allende, 2010).

En el momento de tomar una decisión, el consumidor sopesa una serie de argumentos a favor y en contra de la conducta a llevar a cabo, argumentos que proceden de experiencias anteriores y que guían la toma de decisiones en forma de refuerzo o alarma (Damasio, 2006: 205).

Si se tiene en cuenta la idea de que los consumidores dotan de significado a los productos y a las marcas, es necesario distinguir entre los aspectos manifiestos, salientes y conscientes de las marcas, es decir sus atributos objetivos, y sus propiedades latente simbólicas y muy inconscientes (Batey, 2013). Así por ejemplo, los pensamientos relacionados con la felicidad, el bienestar, el éxito, el placer o la alegría activan y refuerzan determinados circuitos neuronales (Braidot, 2012).

Esto es explicado por Damasio en su Teoría del Marcador Somático. Así según esta teoría, las emociones ante un número potencialmente ilimitado de argumentos a favor y en contra permite de forma automática que se descarten una serie de opciones y se elijan otras, de manera que se tome una decisión en un tiempo apropiado. Si no fuera por las emociones, por tanto, la decisión puramente racional de tomar una decisión se dilataría de forma desmedida en el tiempo (Damasio, 2010: 141). 


\section{Neurobiología del marcador somático}

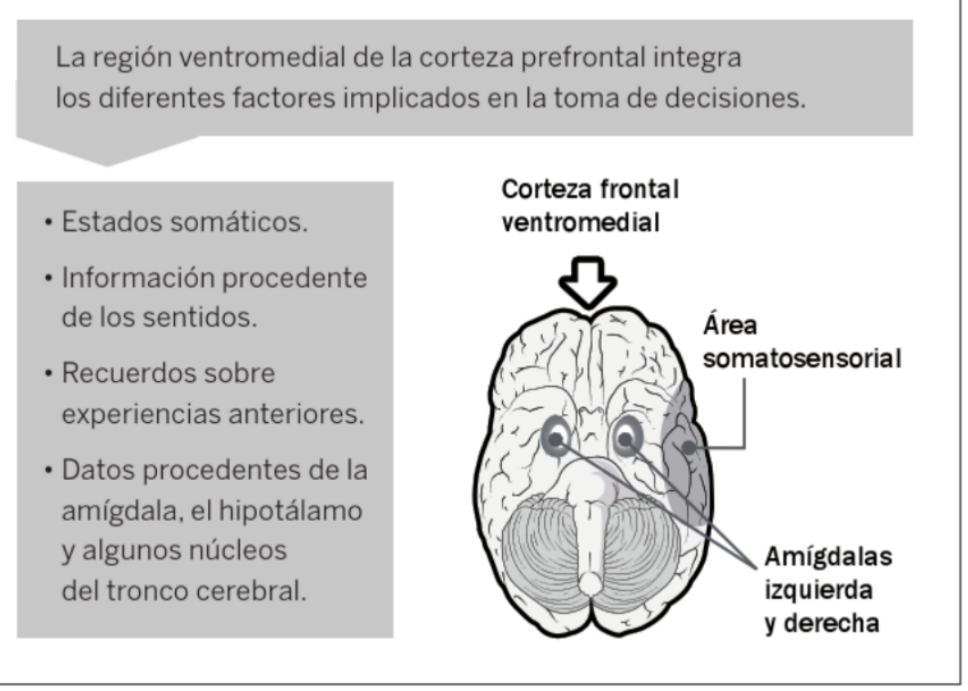

Ilustración 3. Diagrama resumen Teoría Marcador Somático de Antonio Damasio (Fuente: Damasio, 2010).

De esta forma, según las neurociencias la emoción es la que termina por inclinar la balanza en el momento de tomar una decisión ante la imposibilidad de valorar de forma racional la enorme e incesante cantidad de información que llega mediante los sentidos (Punset, 2005: 62). Inicialmente, la información sensorial es procesada por el cerebro sin ningún tipo de componente emocional. Sólo cuando dicha información alcanza ciertas áreas, los llamados "circuitos límbicos", es cuando adquiere la tonalidad afectiva y emocional (Mora et al., 2004).

La neurociencia ha puesto en evidencia que las áreas cerebrales encargadas del raciocinio están estrechamente ligadas a las áreas en las que residen las emociones por medio de conexiones neuronales (Martín, 2014). De esta forma, son numerosas las estructuras que intervienen en el complejo proceso de la toma de decisiones. Algunas de las zonas que se demostrado que tienen participación son algunas partes del neocortex, como las zonas ventromedial y orbitofrontal de la corteza prefrontal, la corteza cingulada y la corteza temporal, así como estructuras subcorticales como la amígdala, el nucleus accumbens, el hipotálamo y algunas estructuras del tallo cerebral (Berridge y Winkielman, 2003)

Las respuestas emocionales son producidas y controladas a nivel cerebral en gran parte por la amígdala (Ríos-Flórez y Cardona-Agudelo, 2016), que consiste en un complejo de diferentes núcleos neuronales localizado en la parte anterior de los lóbulos temporales del cerebro (Morgado y Cuquerella, 2015).

Esta gran influencia, es debido a que las vías neuronales que dirigen la información desde la amígdala hacia la corteza presentan un nivel mucho mayor de neuronas que aquellas que actúan en sentido contrario (aproximadamente diez veces). En relación a esto LeDoux, experto en el estudio de las emociones, descubrió en 1996 que existe un relevo neuronal que va directamente del tálamo a la amígdala, por lo que llega información de forma muy rápida procedente de los sentidos (Braidot, 2012).

De esta forma, la mezcla de emoción y de argumentación resulta fundamental en la persuasión comercial, pues las áreas cerebrales relacionadas con las emociones están unidas mediante haces neuronales a las zonas responsables del raciocinio, y ambas son necesarias y actúan conjuntamente a la hora de tomar decisiones. Las decisiones que son sopesadas exclusivamente de forma racional suelen terminar en fracaso, pues los seres humanos nos basamos en las emociones para tomar nuestras decisiones (Martín, 2014). Bauman resume esta idea expresándolo de la siguiente forma: "Apuesta a la irracionalidad de los consumidores, y no a sus decisiones bien informadas tomadas en frío; apuesta a despertar la emoción consumista, y no a cultivar la razón" (2007: 41).

\subsection{La memoria y el proceso de compra}

Uno de los retos a los que se enfrentan los profesionales de la publicidad y los anunciantes, es poder crear marcas memorables, es decir, con la suficiente relevancia para que sean almacenadas en la memoria del consumidor a largo plazo, ya que una marca memorable presenta más posibilidades de ser comprada. Esto fue demostrado por Young en 2009, quien realizó un experimento que probó que los anuncios con mayor éxito consiguieron mayores índices de momentos recordados (Serrano y De Balanzó, 2012)

La mayoría de las respuestas emocionales son aprendidas, siendo la amígdala una estructura de gran importancia en el condicionamiento 0 asociación entre los estímulos o situaciones originalmente neutras y las circunstancias emocionales a las que quedan ligadas (Morgado y Cuquerella, 2015). De esta forma, Liberman et al. (2009) concluyeron que la felicidad y la memoria tienen una estrecha correlación, al influir la primera sobre la segunda.

León y Olabarría (1993) exponen que el aprendizaje no se limita a lo memorístico, sino que puede implicar también cambios de conducta y una interiorización de gustos y preferencias. Por ejemplo, la relación entre una marca y un consumidor que permanece en el tiempo supone una conducta motivada por un aprendizaje. De esta forma, el significado que tiene una marca para un individuo es resultante de un proceso que tiene lugar en gran parte a nivel inconsciente al comparar los estímulos sensoriales, emocionales y cognoscitivos que emiten las marcas con patrones internalizados que se encuentran almacenados en el cerebro. El significado resultante determina su experiencia diaria influyendo en su comportamiento 
González Garrido y Ramos Loyo (2006) apuntan a que se recuerda mejor aquello en lo que se pone más atención, siendo las emociones un catalizador de la atención hacia un estímulo. Las emociones, por tanto, tienen un fuerte impacto en la cognición. En el caso concreto de la atención, proceso cognitivo que permite focalizar los recursos limitados de procesamiento que posee el cerebro en la información relevante, los estímulos emocionales son procesados de manera preferente y automática, aún cuando son irrelevantes para la tarea en curso. Este procesamiento preferente tiene su origen en la evolución del ser humano, pues dirigir recursos atencionales de manera automática y eficiente hacia una amenaza potencial, facilita una respuesta adecuada que asegure la supervivencia del individuo (Morgado y Cuquerella, 2015).

No obstante, es interesante detenerse sobre la memoria implícita, pues la información puede ser adquirida mientras las personas presentan niveles de atención bajos o incluso también se puede adquirir de forma inconsciente. Esto hace posible que la formación de la memoria se produzca sin esfuerzo consciente. Este aspecto es de gran relevancia para el ámbito de la investigación publicitaria, ya que es posible que un anuncio tenga un efecto sobre la marca y las elecciones de los consumidores, aunque los niveles de atención consciente sean bajos o incluso cuando la publicidad no es ni recordada de forma explícita. Esto fue descrito por Heath en su teoría denominada Low Involvement Processing (LIP). En esta teoría, Heath destaca que las asociaciones implícitas que el consumidor establece con la marca son las que ayudan a tomar las decisiones de consumo, existiendo una influencia sobre las decisiones y percepciones que se poseen entorno a las marcas.

Las nuevas corrientes sobre la conducta del consumidor apuntan a un cambio permanente de las expectativas de los consumidores basadas en las múltiples experiencias de consumo que han tenido, expectativas que influyen en los actos y decisiones de los sujetos. Así la satisfacción no es un fenómeno racional, sino que se encuentra conectada de forma directa con las experiencias, emociones y sentimientos. Esto es explotado por las marcas y el marketing, que presentan sus diferentes productos y servicios como respuesta a esas experiencias, emociones y sentimientos que buscan los consumidores (Olavarrieta, 2002).

Algunos de los primeros estudios realizados sobre la memoria implícita y su relación con el reconocimiento de marca han sido desarrollados por Butler y Berry, quienes demostraron en sus experimentos que el denominado efecto priming hacia marcas desconocidas en tareas de memoria implícita puede dar resultados similares a los observados cuando se comparan con los resultados de las tareas de memoria explícita (Butler y Berry, 2001).

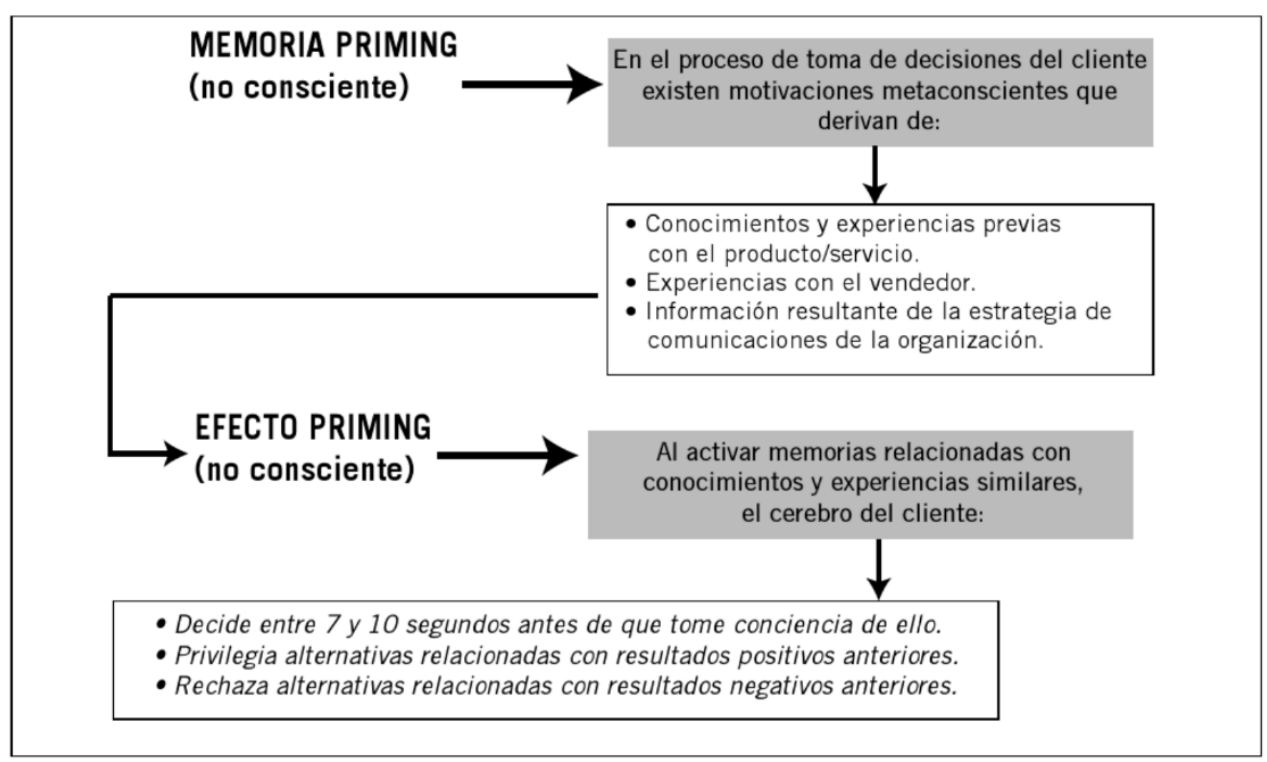

Ilustración 4. Resumen efecto Priming (Fuente: Braidot, 2013: 26).

En relación a esto, también se ha planteado la cuestión de si la comunicación puede cambiar las memorias experienciales, dando a las llamadas ilusiones asociadas por la memoria (Plassmann et al., 2007). Investigaciones con herramientas de medición biométrica parecen apuntar en este sentido, ya que la respuesta de los individuos es muy sensible a los procesos provocados por la integración del contexto.

\section{Conclusiones}

La felicidad ha despertado un gran interés a lo largo de la historia del ser humano, habiendo sido estudiada desde muchas perspectivas y disciplinas diferentes. Si bien existen pocas investigaciones en materia de marketing sobre la felicidad, limitándose la mayor parte de ellas a señalar el gran uso que se hace de este sentimiento por parte de la publicidad y las marcas, son escasos los teóricos que se han lanzado a abordar las implicaciones que tiene su uso para las marcas y el consumo.

Sin embargo, gracias a los avances de las neurociencias se puede intuir, pero no concluir, que la felicidad es sin duda un gran motor de la motivación humana y el consumo. Así, investigadores como Antonio Damasio con su Teoría del Marcador Somático han demostrado la importancia que tienen las emociones sobre las acciones de las personas, así como en la forma en que se enfrentan a los diferentes estímulos en base a experiencias previas.

También se ha podido observar como las emociones positivas tienen un impacto mayor en el recuerdo por parte de los consumidores, así como las relaciones de fidelidad que se generan entorno a las marcas. 
No existe una fórmula única por parte de las marcas para trasladar felicidad a sus consumidores. En relación a esto, es necesario que las marcas no sobreutilicen el concepto de felicidad, pues como consecuencia puede perder valor para los usuarios y consumidores. Por tanto, no se trata de utilizar la felicidad como reclamo publicitario, sino proporcionar la felicidad no como un concepto estandarizado y compacto, sino de una forma única que sea valiosa para los consumidores de la marca.

No obstante, parece existir una serie de patrones comunes que son utilizados para evocar la felicidad. Así, el uso de colores cálidos, imágenes de personas con una vida plena y música armoniosa en los diferentes anuncios emitirá una sensación de felicidad, que ayudará a que la marca se acabe asociando al concepto de felicidad. Además, es importante que exista una coherencia en el posicionamiento y mensaje de felicidad que intenta lanzar la marca a través de sus diferentes canales de comunicación y relación con sus clientes, así como que esta sea una estrategia que sea sostenida en el tiempo.

Para concluir, el conocimiento entorno a la felicidad y cómo influye en el consumo es prácticamente inexistente, lo que abre una importante e interesante vía de investigación para el futuro. El auge del neuromarketing augura la posibilidad de obtener un conocimiento más profundo sobre la felicidad y las implicaciones que tiene este sentimiento sobre el consumo. Esta disciplina ha puesto el foco sobre la importancia de las emociones y los factores que influyen de manera inconsciente en la toma de decisiones por parte de los consumidores. De esta forma, si se consigue demostrar de forma concluyente que la felicidad tiene un verdadero impacto sobre las elecciones de los consumidores, el interés por parte de los académicos, y sobre todo de las marcas, se incrementará de forma exponencial. Pero para ello, antes será necesario realizar avances que permitan un mayor conocimiento entorno a la felicidad y su relación con el consumo, pues son todavía muchas las preguntas sin respuestas que existen entorno a este tema como si ¿es más efectiva la publicidad que evoca la felicidad que aquellos anuncios que apelan otras emociones? ¿Genera engagement la felicidad? ¿Cuáles son los rasgos de las marcas asociadas a la felicidad? ¿Es la felicidad la mejor promesa que se le puede hacer al consumidor? ¿Qué elementos producen felicidad en los consumidores?

\section{Bibliografía}

La felicidad

Allende, V. (2010). La publicidad Emocional e Informativa y su Relación con el recuerdo en la población de adolescentes (Trabajo Fin de Grado). Universidad Siglo XXI.

Álvarez, J. P. (2015). La Ciencia de la emoción en el Marketing. Neuromarketing.la. Recuperado de: https://neuromarketing.la/2015/07/la-cienciade-la-emocion-en-el-marketing-neuromarketing/

Amigot, P. y Aguilar, M. (Trads.) (2003). Traficantes de sueños. Madrid, España.

Andreu, L. (2003). Emociones del consumidor: componentes y consecuencias de marketing. Estudios sobre consumo, 64(1), 9-26. Recuperado de: https://www.researchgate.net/publication/28243564

Araújo, P. M. (2015). Influencia de la experiencia de marca, en el valor de la marca, por vía de la satisfacción y lealtad de clientes (Tesis Doctoral). Universidad Rey Juan Carlos, Madrid. Recuperado de: http://hdl.handle.net/10115/13563

Batey, M. (2013). El significado de la marca: cómo y por qué ponemos sentido a productos y servicios.

Bauman, Z. (2007). Vida de consumo.

Berridge, K. y Winkielman, P. (2003). What is an unconscious emotion? (The case for unconscious" liking"). Cognition and emotion, 17(2), $181-211$.

Braidot, N. (2005). Neuromarketing: neuroeconomía y negocios. Madrid: PuertoNorte Sur.

Braidot, N. (2012). Sácale partido a tu cerebro: todo lo que necesitas saber para mejorar tu memoria, tomar mejores decisiones y aprovechar todo tu potencial.

Braidot, N. (2013). Neuroventas: conozca cómo funciona el cerebro para vender con inteligencia y resultados exitosos.

Butler, L. T. y Berry, D. C. (2001). Implicit memory: Intention and awareness revisited. Trends in Cognitive Sciences, 5(5), $192-197$.

Cabrera, A (2009). Felicidad y aspiraciones crecientes de consumo en la sociedad postmoderna. Revista mexicana de sociología, 71(1), $131-157$. Recuperado de: http://www.redalyc.org/articulo.oa?id=32116011004

Caravaggio, L. (2016). La economía y la felicidad. Estudios Económicos, 33(67), 97-118. Recuperado de: https://dialnet.unirioja.es/servlet/articulo?codigo $=6268042$

Carrillo, C. M. (2017). El Neuromarketing como instrumento para la eficacia de la publicidad en televisión (Tesis Doctoral). Universidad Católica de Murcia, Murcia. Recuperado de: http://hdl.handle.net/10952/2356

Carrillo, S., Feijóo, M. L., Jara, P. y Schellekens, M. (2017). El Papel de la Dimensión Colectiva en el Estudio de la Felicidad. Revista colombiana de psicología, 26(1), 115-129. Recuperado de: https://dialnet.unirioja.es/servlet/articulo?codigo=5846229

Ceruelo, C. y Gutiérrez, A. M. (2003). Eficacia de la Publicidad Emocional. Un Estudio Comparativo entre la Ejecución de Tipo Emocional e Informativa. Nuevas Tendencias en Dirección de Empresas (Documento de Trabajo). Universidad de Valladolid, Valladolid. Recuperado de: https://gredos.usal.es/jspui/handle/10366/75262 
Chicaiza, T. (2012). Vendiendo felicidad: el nuevo paradigma de las marcas. RETOS. Revista de Ciencias de la Administración y Economía, 2(3), 37-51. Recuperado de: http://www.redalyc.org/articulo.oa?id=504550953003

Chiu, C. Y. y Hong, Y. Y. (2013). Social psychology of culture. Psychology Press.

Cisneros, E. A. (2012). Neuromarketing y neuroeconomía: código emocional del consumidor.

Clark, M. S. y Isen, A. M. (1982). Toward understanding the relationship between feeling states and social behavior. Cognitive social psychology, 73 , 108.

Conner, M. y Norman, P. (2005). Predicting health behaviour. McGraw-Hill Education, UK.

Damasio, A. R. (2000). Creación cerebral de la mente. Investigación y Ciencia: Edición Española de Scientific American, 280, 66-71.

Damasio, A. R. (2006). L'erreur de Descartes: la raison des émotions. Odile Jacob.

Damasio, A. (2010). Autre moi-même (L'): Les nouvelles cartes du cerveau, de la conscience et des émotions. Odile Jacob.

Dávila, V. (2013). Neuroresearch, Neurociencias y Marketing (Tesis Fin de Máster). Universidad Nacional de la Plata, Buenos Aires. Recuperado de: http://sedici.unlp.edu.ar/bitstream/handle/10915/35300/Documento_completo_.pdf?sequence=1

De Balanzo, C. y Sabaté, J. (2006). Neurociencias y publicidad: la nueva frontera de la persuasión. En IV Congrés Internacional Comunicació i Realitat. Recuperado de: https://www.researchgate.net/publication/237366576_Neurociencias_y_publicidad_la_nueva_frontera_de_la_persuasion

De Balanzó, C., Serrano, N. y Scamell-Katz, S. (2010). Damasio: a starting point for integrating neuroscience findings into retail research. ESOMAR Congress.

De los Ríos, A. (2016). Felicidad y economía: la felicidad como utilidad en la economía. Equidad y Desarrollo, 1(26), 115-143. Recuperado de: https://revistas.lasalle.edu.co/index.php/ed/article/view/3700

Eada (2015, 13 de febrero). Marcas que hacen felices a los consumidores. Eada. Recuperado de: http://blogs.eada.edu/2015/02/13/marcasquehacen-felices-a-sus-clientes/

Eguizábal, R. (2007). Teoría de la publicidad. Madrid: Cátedra.

Feenstra, R. A. (2013). La irrupción de la neuropublicidad y sus debates éticos. Revista Internacional de Filosofía, 1(59), 45-56. Recuperado de: https://www.researchgate.net/publication/305773036

Flórez, J. A. R., \& Agudelo, V. C. (2016). Ruptura del paradigma subcortical en los procesos emocionales. Poiésis, (31), 132-140.

Funahashi, S. (2011). Brain mechanisms of happiness. Psychologia, 4(54), 222-233. Recuperado de: https://www.researchgate.net/publication/274501057_Brain_mechanisms_of_happiness

Gardner, M. P. (1985). Mood states and consumer behavior: A critical review. Journal of Consumer Research, 12(3), 281-300.

González Hernández, E. M., Orozco Gómez, M. y Barrios, A. D. L. P. (2011). El valor de la marca desde la perspectiva del consumidor. Estudio empírico sobre preferencia, lealtad y experiencia de marca en procesos de alto y bajo involucramiento de compra. Contaduría y administración, 235 , 217-239.

Holbrook, M. B. y Batra, R. (1987). Assessing the role of emotions as mediators of consumer responses to advertising. Journal of Consumer Research, 14(3), 404-420.

Hsee, C. K., Yang, Y., Li, N. y Shen, L. (2009). Wealth, warmth, and well-being: Whether happiness is relative or absolute depends on whether it is about money, acquisition, or consumption. Journal of Marketing Research, 46(3), 396-409.

Imfeld, J. (2015). El Marketing de la Felicidad: Análisis de la construcción de las marcas a partir del discurso de la felicidad (Tesis fin de Grado). Universidad de Buenos Aires, Buenos Aires. Recuperado de: http://bibliotecadigital.econ.uba.ar/?c=tpos\&a=d\&d=1502-0796_ImfeldJ

Isen, A. M., Labroo, A. A. y Durlach, P. (2004). An influence of product and brand name on positive affect: Implicit and explicit measures. Motivation and Emotion, 28(1), 43-63.

Klaric, J. (2016). Véndele a la mente, no a la gente. Editorial Paidós

Martín, A. (2014). La retórica clásica y la neurociencia: las emociones y la persuasión. Rétor.

León, J. L. y Olabarría, E. (1993). Conducta del Consumidor y Marketing. Buenos Aires: Deusto.

Lindstrom, M. (2010). Buyology. Verdades y mentiras de por qué compramos. Barcelona: Gestion2000.

López, J. C. (2007). Publicidad emocional: estrategias creativas. Comunicación y hombre: Revista interdisciplinar de ciencias de la comunicación y humanidades, 3, 143-146.

Lysonski, S. (2014). Receptivity of young Chinese to American and global brands: psychological underpinnings. Journal of Consumer Marketing, 31(4), 250-262. Recuperado de: https://dialnet.unirioja.es/servlet/articulo?codigo=4751820 
Martínez, E. y Raya P. (2015). La Publicidad emocional de Campofrío como Trending Topic. En F. J. Durán y E. Said, TIC y Sociedad Digital: Educación, Infancia y Derecho, pp. 143-150. Granada: Comares Editorial. Recuperado de: https://www.researchgate.net/publication/285577706_TIC_y_Sociedad_Digital_Educacion_Infancia_y_Derecho

Maturana, H. R. (1990). Emociones y lenguaje en educación y política. JC Sáez Editor.

Mogilner, C. y Aaker, J. (2009). "The time vs. money effect": Shifting product attitudes and decisions through personal connection. Journal of Consumer Research, 36(2), 277-291.

Mogilner, C., Aaker, J. y Kamvar, S. (2011). How Happiness Affects Choice. Journal of Consumer Research, 2(39), 429-443. Recuperado de: https://academic.oup.com/jcr/article/39/2/429/1798974

Moltó, J., Montañés, S., Gil, R. P., Cabedo, P. S., Verchili, M. C. P., Irún, M. P. T., ... y Castellar, J. V. (1999). Un método para el estudio experimental de las emociones: el International Affective Picture System (IAPS). Adaptación española. Revista de psicología general y aplicada: Revista de la Federación Española de Asociaciones de Psicología, 52(1), 55-87.

Monge, S. y Fernández, V. (2012). Neuromarketing: Tecnologías, Mercado y Retos. Pensar la Publicidad. Revista Internacional de Investigaciones Publicitarias, 5(2). 19-42. Recuperado de: https://www.researchgate.net/publication/268268697

Montagut, X. (Ed.). (2007). Supermercados, no gracias: grandes cadenas de distribución: impactos y alternativas (Vol. 251). Icaria Editorial.

Morgado, B. I. y Cuquerella, F. À. (2015). Neurociencia afectiva.

Moya, I. (2015). Emociones y género en el proceso de toma de decisiones de compra. Estudio realizado con resonancia magnética funcional (Tesis Doctoral). Universidad Complutense, Madrid.

Muñiz, J.A. y Álvarez, A. (2013). Comunicación positiva: la comunicación organizacional al servicio de la felicidad. Vivat Academia, 1(124), 90-109. Recuperado de: https://dialnet.unirioja.es/servlet/articulo?codigo=5004636

Nicolao, L., Irwin, J.R y Goodman, J. K (2009). Happiness for Sale: Do Experiential Purchases Make Consumers Happier than MaterialPurchases? Journal of Consumer Research, 1(36), 188-198. Recuperado de: https://www.researchgate.net/publication/227630698_Happiness_for_Sale_Do_Experiential_Purchases_Make_Consumers_Happier_than_Material

Olavarrieta, S. (2002). ¿Por qué tiene valor su marca para los consumidores? Revista Economía \& Administración, 143, 21 -29.

Pellicer, M. T. (2013). La promesa de felicidad en los mensajes de la publicidad comercial. Pensar la Publicidad, 1(7), 13-23. Recuperado de: https://revistas.ucm.es/index.php/PEPU/article/viewFile/42434/40368

Plassmann, H., O'Doherty, J. y Rangel, A. (2007). Orbitofrontal cortex encodes willingness to pay in everyday economic transactions. Journal of Neuroscience, 27(37), 9984-9988.

Podoshen, J. S. y Andrzejewski, S. A. (2012). An examination of the relationships between materialism, conspicuous consumption, impulse buying, and brand loyalty. Journal of Marketing Theory and Practice, 20(3), 319-334.

Pretel, M. (2017). La conexión emocional entre marca y consumidor. Análisis del caso Apple y Samsung en el público adolescente y joven (Tesis Doctoral). Universidad Complutense, Madrid. Recuperado de: http://eprints.ucm.es/41721/1/T38560.pdf

Punset, E. (2005). El viaje a la felicidad. Las nuevas claves científicas. Barcelona: Ediciones Destino.

Ramos Loyo, J. (2006). Influencia de las emociones en los procesos cognoscitivos. En AA González Garrido y J. Ramos Loyo, La atención y sus alteraciones. Del cerebro a la conducta. México: El Manual Moderno.

Restrepo J. C, Rojas, J. A., Ortiz, C. P., Muñoz, D. A., Uribe, J. C., Gómez, F., Zapata W. y Vergara, C. E. (2012). ¿Qué es la felicidad para el cerebro?: una visión neurocientífica. En J. C. Restrepo, La Felicidad: Perspectivas y Abordajes desde las Ciencias Sociales, pp. 103-115. Itagüí: Serie Lasallista Investigación y Ciencia. Recuperado de : http://repository.lasallista.edu.co/dspace/bitstream/10567/453/1/felicidad_montaje.pdf

Rubiano, J. (2016, 7 de junio). Cómo nuestro cerebro percibe y reconoce un logotipo. Inbrain Marketing Sensorial. Recuperado de: https://www.inbrain.co/single-post/2016/06/07/C\%C3\%B3mo-nuestro-cerebro-percibe-y-reconoce-un-logotipo

Sarmientos, L. F. y Ríos, J.A. (2017). Bases neurales de la toma de decisiones e implicación de las emociones en el proceso. Revista Chile Neuropsicología, 2(12), 32-37. Recuperado de: http://www.neurociencia.cl/dinamicos/articulos/128889-02 alexander rios-florez.pdf

Schuschny, A. (2009). Democracia Recargada: en la Red se puede. Crítica, 59(959), $42-47$.

Šeinauskienè, B., Maščinskienè, J. y Jucaitytè, I. (2015). The relationship of happiness, impulse buying and brand loyalty. Procedia - Social and Behavioral Sciences, 1(213), 687-693. Recuperado de: https://www.sciencedirect.com/science/article/pii/S1877042815058425

Senik, C. (2008). Ambition and jealousy: Income interactions in the 'Old'Europe versus the 'New'Europe and the United States. Economica, 75(299), 495-513.

Serrano, N. y De Balanzó, C. (2012). Neuromarketing y Memoria: Implicaciones para la Comunicación Publicitaria. Pensar la Publicidad. Revista Internacional de Investigaciones Publicitarias, 6(2), 297-313. Recuperado de: http://revistas.ucm.es/index.php/PEPU/article/view/41217 
Silvera, D. H., Lavack, A. M. y Kropp, F. (2008). Impulse buying: the role of affect, social influence, and subjective wellbeing. Journal of Consumer Marketing, 25(1), 23-33.

Soto, R. (2014, 14 de agosto). ¿Cómo procesa tu cerebro un logotipo?. Roxana Soto. Recuperado de: http://roxanasoto.me/praesent-bibendumipsum-in-ultricies-accumsan-2/

Van Boven, L. y Gilovich, T. (2003). To do or to have? That is the question. Journal of Personality and Social Psychology, 85(6), 1193.

Woo, H. y Ahn, H. J. (2015). Big Five Personality and Different Meanings of Happiness of Consumers. Economics and Sociology, 8(3), 145-154. Recuparado https://www.researchgate.net/publication/284709246_Big_Five_Personality_and_Different_Meanings_of_Happiness_of_Consumers

Zaltman, G. (2004). Cómo piensan los consumidores. Barcelona: Urano.

\section{Cómo citar este artículo en bibliografías - How to cite this article in bibliographies / references:}

CANOREA-TIRALASO, H; CRISTÓFOL-RODRÍGUEZ, C. (2018): "La felicidad en publicidad desde la perspectiva del neuromarketing". En Revista de la Asociación Española de Investigación de la Comunicación, vol. 5, número 10, pp. 47-57. 